University of Wollongong

Research Online

Australian Institute for Innovative Materials -

Papers

Australian Institute for Innovative Materials

$1-1-2015$

Sodium-difluoro(oxalato)borate (NaDFOB): A new electrolyte salt for $\mathrm{Na}$-ion batteries

Juner Chen

Chinese Academy of Sciences

Zhenguo Huang

University of Wollongong, zhenguo@uow.edu.au

Caiyun Wang

University of Wollongong, caiyun@uow.edu.au

Spencer H. Porter

University of Wollongong, sp733@uowmail.edu.au

Baofeng Wang

University of Wollongong, bwang@uow.edu.au

See next page for additional authors

Follow this and additional works at: https://ro.uow.edu.au/aiimpapers

Part of the Engineering Commons, and the Physical Sciences and Mathematics Commons

Research Online is the open access institutional repository for the University of Wollongong. For further information contact the UOW Library: research-pubs@uow.edu.au 


\title{
Sodium-difluoro(oxalato)borate (NaDFOB): A new electrolyte salt for $\mathrm{Na}$-ion batteries
}

\author{
Abstract \\ A new electrolyte salt, sodium-difluoro(oxalato)borate (NaDFOB), was synthesized and studied, which \\ enables excellent reversible capacity and high rate capability when used in $\mathrm{Na} / \mathrm{Na} 0.44 \mathrm{MnO}_{2}$ half cells. \\ $\mathrm{NaDFOB}$ has excellent compatibility with various common solvents used in $\mathrm{Na}$-ion batteries, in strong \\ contrast to the solvent dependent performances of $\mathrm{NaClO}_{4}$ and $\mathrm{NaPF}_{6}$. In addition, NaDFOB possesses \\ good stability and generates no toxic or dangerous products when exposed to air and water. All these \\ properties demonstrate that NaDFOB could be used to prepare high performance electrolytes for \\ emerging $\mathrm{Na}$-ion batteries.

\section{Keywords} \\ na, salt, electrolyte, ion, nadfob, sodium, borate, difluoro, batteries, oxalato \\ Disciplines \\ Engineering | Physical Sciences and Mathematics

\section{Publication Details} \\ Chen, J., Huang, Z., Wang, C., Porter, S., Wang, B., Lie, W. \& Liu, H. (2015). Sodium-difluoro(oxalato)borate \\ (NaDFOB): A new electrolyte salt for Na-ion batteries. Chemical Communications, 51 (48), 9809-9812.

\section{Authors} \\ Juner Chen, Zhenguo Huang, Caiyun Wang, Spencer H. Porter, Baofeng Wang, Wilford Lie, and Hua-Kun \\ Liu
}




\title{
Sodium-difluoro(oxalato)borate (NaDFOB): A new electrolyte salt for Na-ion batteries $\dagger$
}

\author{
Juner Chen, ${ }^{a}$ Zhenguo Huang, ${ }^{a, *}$ Caiyun Wang, ${ }^{b}$ Spencer Porter, ${ }^{a}$ Baofeng Wang, ${ }^{a, c}$ Wilford Lie, ${ }^{d}$ and \\ Hua Kun Liu ${ }^{a}$
}

\author{
${ }_{5}$ Received (in $\left.X X X, X X X\right) X t h X X X X X X X X X 20 X X$, Accepted Xth $X X X X X X X X X 20 X X$ \\ DOI: 10.1039/b000000x
}

A new electrolyte salt, sodium-difluoro(oxalato)borate (NaDFOB), was synthesized and studied, which offers excellent reversible capacity and high rate capability when 10 used in $\mathrm{Na} / \mathrm{Na}_{0.44} \mathrm{MnO}_{2}$ half cells. $\mathrm{NaDFOB}$ has excellent compatibility with various common solvents used in $\mathrm{Na}$-ion batteries, in strong contrast to the solvent dependent performances of $\mathrm{NaClO}_{4}$ and $\mathrm{NaPF}_{6}$. In addition, NaDFOB possesses good stability and generates no toxic or dangerous 15 products when exposed to air and water. All these properties demonstrate that NaDFOB could be used to prepare high performance electrolyte for emerging Na-ion batteries.

Owing to the low cost and high natural abundance of sodium 20 (Na), Na-ion batteries (NIBs) have been extensively studied very recently. ${ }^{1-7}$ There has been impressive progress in the exploration of cathode materials for NIBs, such as various oxides and polyanionic compounds, ${ }^{8-10}$ as well as anode materials, including hard carbon, alloys, metal oxides, and other sodiatable 25 materials. ${ }^{11-14}$ The electrolyte is a critical component of NIBs, yet has not received comparable interest, which could hamper the development of the NIBs. ${ }^{15,16}$

The most common electrolyte formulation for NIBs is $\mathrm{NaClO}_{4}$ or $\mathrm{NaPF}_{6}$ dissolved in carbonate solvents such as ethylene 30 carbonate (EC) and/or propylene carbonate (PC) because of their very high dielectric constants, large electrochemical windows, and low volatilities. ${ }^{17}$ Other salts, such as sodiumbis(tri-fluoromethane)sulfonimide (NaTFSI), $\mathrm{NaSO}_{3} \mathrm{CF}_{3}$, $\mathrm{NaSbF}_{6}, \mathrm{NaAsF}_{6}, \mathrm{NaBF}_{4}, \mathrm{NaCF}_{3} \mathrm{CO}_{2}$, and $\mathrm{Na}\left(\mathrm{CH}_{3}\right) \mathrm{C}_{6} \mathrm{H}_{4} \mathrm{SO}_{3}$, 35 have also been studied. ${ }^{18,19}$ NaTFSI and $\mathrm{NaSO}_{3} \mathrm{CF}_{3}$-based electrolytes have a limited electrochemical window, however; ${ }^{20}$, ${ }^{21} \mathrm{NaAsF}_{6}$ is toxic; $\mathrm{NaBF}_{4}, \mathrm{NaCF}_{3} \mathrm{CO}_{2}$, and $\mathrm{Na}\left(\mathrm{CH}_{3}\right) \mathrm{C}_{6} \mathrm{H}_{4} \mathrm{SO}_{3}$ electrolytes have low conductivity. ${ }^{19}$ Excellent studies have been carried out by A. Ponrouch et al. on the optimization of NIB 40 electrolyte formulations based upon $\mathrm{NaClO}_{4}, \mathrm{NaPF}_{6}$, or NaTFSI. ${ }^{20}$ The binary EC:PC mixture has emerged as the best formulation for $\mathrm{NaClO}_{4}$ and $\mathrm{NaPF}_{6}$, and been used to test the performance of $\mathrm{Na} /$ hard carbon cells. $^{20}$ Adding dimethyl carbonate (DMC) to EC:PC was found to improve the ${ }_{45}$ performance of electrolytes containing these two salts. ${ }^{22} \mathrm{NaClO}_{4}$ is potentially explosive, however, and $\mathrm{NaPF}_{6}$ is sensitive to moisture, evolving highly corrosive HF. Since NIBs have been largely considered for stationary energy storage due to its lower power density, and the deployment of NIB stacks would normally
50 require a large quantity of electrolyte, an electrolyte that is both highly safe and efficient is critical.

In our efforts, initial focus was on sodium-bis(oxalato)borate (NaBOB), whose $\mathrm{Li}$-analogue has aroused intense interest in the lithium-ion battery (LIB) research community. ${ }^{23}$ NaBOB's 55 limited solubility in carbonate solvents, however, rules out its application in NIBs. ${ }^{19,24}$ The replacement of an oxalate subunit in LiBOB with two fluorides forms a lithiumdifluoro(oxalato)borate (LiDFOB) with improved solubility due to the presence of more electron-withdrawing fluorine. ${ }^{25}$ The 60 resulting more delocalized charge gives the anion less affinity for $\mathrm{Li}^{+}$, causing better conductivity. ${ }^{16,26}$ Therefore, the present work is focused on the synthesis and testing of sodiumdifluoro(oxalato)borate $\left(\mathrm{NaC}_{2} \mathrm{O}_{4} \mathrm{BF}_{2}\right.$, denoted as $\left.\mathrm{NaDFOB}\right)$ for emerging NIBs.

65 NaDFOB was obtained from the reaction of sodium-oxalate $\left(\mathrm{Na}_{2} \mathrm{C}_{2} \mathrm{O}_{4}\right)$ with boron-trifluoride-diethyl-etherate $\left(\mathrm{BF}_{3} \cdot\right.$ ether $)$ in acetonitrile. Elemental analysis shows that the white NaDFOB powder contains 23.67 wt.\% F and 7.21 wt.\% B, which matches well with the theoretical value (23.75 wt.\% $\mathrm{F}$ and $6.87 \mathrm{wt}$. \% B in $70 \mathrm{NaC}_{2} \mathrm{O}_{4} \mathrm{BF}_{2}$ ). The formation of the $\mathrm{DFOB}^{-}$anion was evidenced by Fourier transform infrared (FTIR) spectroscopy (Fig. S1, Supporting Information). The IR absorption band observed at $1373.32 \mathrm{~cm}^{-1}$ is assigned to the $\mathrm{B}-\mathrm{O}$ characteristic stretching vibration that has also been observed at $1372.14 \mathrm{~cm}^{-1}$ in 75 LiDFOB. $^{27}$ The broad bands at 1122.57 and $1087.85 \mathrm{~cm}^{-1}$ are associated with relatively uncoupled $\mathrm{O}-\mathrm{B}-\mathrm{O}$ and $\mathrm{F}-\mathrm{B}-\mathrm{F}$ stretching vibrations, respectively. The formation of the $\mathrm{DFOB}^{-}$ anion is also evidenced by the ${ }^{11} \mathrm{~B}$ nuclear magnetic resonance (NMR) spectra (Fig. S2). A strong peak at $2.8 \mathrm{ppm}$ corresponding 80 to $\mathrm{NaDFOB}$ was observed, as well as a weak peak at $-1.5 \mathrm{ppm}$ (due to $\left.\mathrm{NaBF}_{4}\right) \cdot{ }^{28}$ There is no change in the spectrum after 120 days of storage at room temperature.

The crystal structure of NaDFOB was determined from the powder X-ray diffraction (XRD) data by indexing the peaks, ${ }_{85}$ simulated annealing, and Rietveld refinement [XRD pattern (Fig. S3), structure solutions, and crystallographic information (Tables S1 and S2)]. NaDFOB possesses a tetragonal structure with lattice parameters $a=7.7316(1) \AA, c=8.5343(1) \AA$, and $V=$ 510.16(1) $\AA^{3}$. The structure can be viewed as chains of $90-\mathrm{DFOB}-\mathrm{Na}-$ along the $c$-axis, with neighbouring $\mathrm{DFOB}^{-}$anions perpendicular to each other (Fig. 1). The $\mathrm{Na}^{+}$cation is coordinated by four oxygen and four fluorine atoms [Fig. S4(a)]. 
Each $\mathrm{DFOB}^{-}$anion is coordinated to six $\mathrm{Na}^{+}$cations, with two terminal carbonyl oxygens coordinated to three $\mathrm{Na}^{+}$cations and fluorine atoms coordinated to the remaining three $\mathrm{Na}^{+}$cations [Fig. S4(b)]. Among these, there are two oxygen atoms and two 5 fluorine atoms from neighbouring chains that bind the layer into a framework, as shown in Fig. S5.

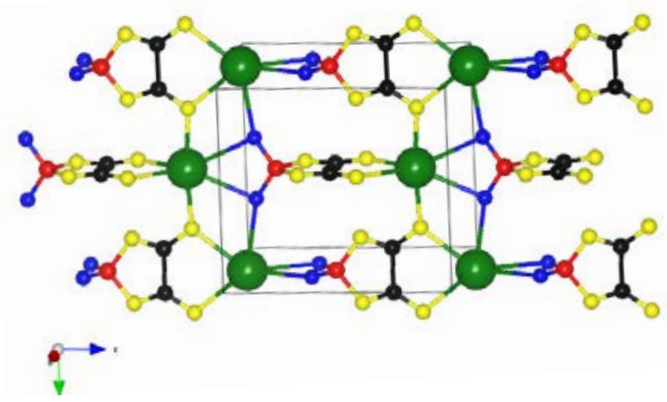

Fig.1 View along the [100] direction showing bonded chains in the crystal structure of NaDFOB. Na, C, O, B, and F are represented by 10 green, black, yellow, red, and blue spheres, respectively.

Electrolyte is essential for proper functioning of NIBs. To test the performance of the NaDFOB-based electrolytes, electrolytes with 1.0 M NaDFOB in EC:DEC, EC:DMC, EC:PC, PC, and PC $+5 \%$ FEC were prepared in this work. Differential scanning 15 calorimetry (DSC) was used to study the melting points, which determine the operating temperature window of the electrolytes. The electrolytes were first cooled down to $-70{ }^{\circ} \mathrm{C}$ and then heating up to $80^{\circ} \mathrm{C}$ at a ramp rate of $10^{\circ} \mathrm{C} \mathrm{min}^{-1}$. For $1.0 \mathrm{M} \mathrm{NaX}$ $\left(\mathrm{X}=\mathrm{DFOB}, \mathrm{ClO}_{4}\right.$, and $\left.\mathrm{PF}_{6}\right)$ in EC:DEC electrolyte, two 20 endothermic peaks were found during the heating process (Fig. S6). The first endothermic peak related to the crystallization shifts from -33.7 , to -15.5 , to $-44.5^{\circ} \mathrm{C}$ for $\mathrm{NaClO}_{4}, \mathrm{NaPF}_{6}$, and NaDFOB, respectively. When the salts were dissolved in EC:DMC binary solvent, this endothermic peak was observed at ${ }_{25}-30.8,-6.5$, and $-15.3{ }^{\circ} \mathrm{C}$ for $\mathrm{NaClO}_{4}, \mathrm{NaPF}_{6}$, and $\mathrm{NaDFOB}$, respectively. These results indicate that the melting points of EC-based binary solvents are predominantly affected by the high melting point of EC $\left(\sim 36.4{ }^{\circ} \mathrm{C}\right)$. Solidification was not observed in PC-based electrolyte, which could be advantageous for 30 application at low temperatures.

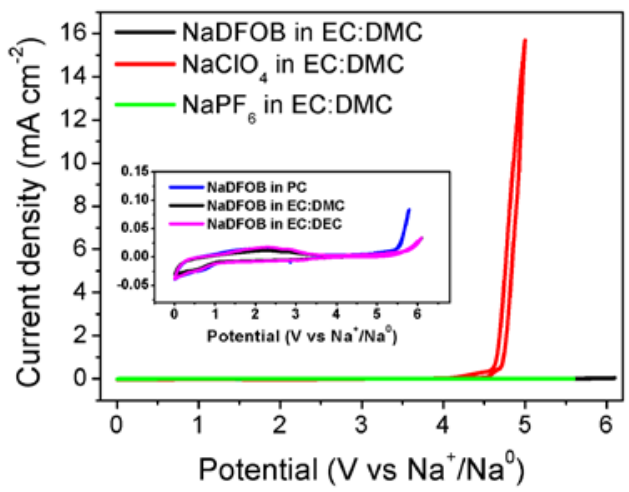

Fig. $2 \mathrm{CVs}$ of the electrolytes with $1.0 \mathrm{M} \mathrm{NaX}\left(\mathrm{X}=\mathrm{DFOB}, \mathrm{ClO}_{4}\right.$, and $\mathrm{PF}_{6}$ ) in EC:DMC at room temperature at a scan rate of $1 \mathrm{mV} \cdot \mathrm{s}^{-1}$. Inset shows the CV curves of the electrolytes with NaDFOB in PC, EC:DEC, 35 and EC:DMC, respectively.
The electrochemical stability window of the electrolytes at room temperature was investigated using stainless steel as the working electrode and $\mathrm{Na}$ as the counter and reference electrode. The CVs collected for NaDFOB-based electrolytes are shown in ${ }_{40}$ Fig. 2. The initial decomposition voltages of $1.0 \mathrm{M}$ NaDFOB in PC, EC:DEC, and EC:DMC are 5.51, 5.76, and $5.79 \mathrm{~V}$, respectively. Obviously, the electrochemical window of NaDFOB in EC:DMC electrolyte is wider than that of $\mathrm{NaClO}_{4}$ and comparable to that of $\mathrm{NaPF}_{6}$. Similar results were found in the ${ }_{45}$ EC:DEC-based electrolytes (Fig. S7). Very weak current was found for NaDFOB-based electrolytes over the whole potential range, and the current is high in $\mathrm{NaClO}_{4}$-based electrolytes. The wide electrochemical stability window promotes NaDFOB-based electrolytes to be good candidates for high voltage NIBs.

50 Pre-sodiated manganese oxide, $\mathrm{Na}_{0.44} \mathrm{MnO}_{2}$ (also known as $\mathrm{Na}_{4} \mathrm{Mn}_{9} \mathrm{O}_{18}$ ), has been thoroughly investigated over the years, because of its attractive large-size tunnels for sodium ion (de)insertion. ${ }^{29-32}$ In most cases, a $\mathrm{Na} / \mathrm{Na}_{0.44} \mathrm{MnO}_{2}$ half cell is coupled with $\mathrm{NaClO}_{4}$-based electrolyte. The discharge capacities 55 are in the range of $80-130 \mathrm{~mA} \mathrm{~h} \mathrm{~g}^{-1}$ and deteriorate dramatically at high rates. In this work, micron-sized $\mathrm{Na}_{0.44} \mathrm{MnO}_{2}$ obtained by solid-state sintering was used as the cathode material. Fig. 3(a) shows the first cycle galvanostatic test profiles of $\mathrm{Na} / \mathrm{Na}_{0.44} \mathrm{MnO}_{2}$ half cells with $1.0 \mathrm{M}$ NaDFOB-based electrolyte at $15 \mathrm{~mA} \mathrm{~g}^{-1}$. 60 Four and six voltage plateaus are distinctly observed in the charge and discharge curves, respectively, indicating a multiphase evolution. ${ }^{33}$ It is believed that the presence of multiphase states is strongly associated with not only the chemical potential, but also peculiar $\mathrm{Na}^{+} /$vacancy ordering. ${ }^{34}$ In the range of $2.0-4.0 \mathrm{~V}$, the 65 cells with NaDFOB in EC:DEC, EC:DMC, EC:PC, PC, and PC + $5 \%$ FEC exhibit capacities of 115, 110, 103, 112, and $112 \mathrm{mAh}$ $\mathrm{g}^{-1}$, respectively.

Rate and cycling performances were investigated, as shown in Fig. 3(b). Compared with $\mathrm{NaClO}_{4}$ and $\mathrm{NaPF}_{6}$-based electrolytes, 70 cells with NaDFOB-based electrolytes show much higher discharge capacities, except for the cells with $\mathrm{NaClO}_{4}$ in EC:PC at 15 and $50 \mathrm{~mA} \mathrm{~g}^{-1}$. For most solvents, the capacities of the cells with $\mathrm{NaClO}_{4}$ - and $\mathrm{NaPF}_{6}$-based electrolytes fade dramatically at higher rates. On the contrary, all the cells with various 75 NaDFOB-based electrolytes demonstrate excellent rate capability and capacity retention, with nearly a full recovery after 143 cycles, showing superior performances to those of $\mathrm{NaClO}_{4}$ and $\mathrm{NaPF}_{6}$-based electrolytes in this study and in the reported results. ${ }^{29-31}$ The Coulombic efficiencies of the $\mathrm{Na} / \mathrm{Na}_{0.44} \mathrm{MnO}_{2}$ 80 half cells are shown in Fig. S8. NaDFOB-based electrolytes show very high Coulombic efficiencies (close to 100\%) without fading during the cycling, which are higher than those of $\mathrm{NaClO}_{4}-$ and $\mathrm{NaPF}_{6}$-based electrolytes. The high compatibility of NaDFOB with all the common solvents currently used for ${ }_{85}$ NIBs in the literature is highly valuable, since this could enable the use of NaDFOB in different environments. In contrast, the performances of cells with $\mathrm{NaClO}_{4}-$ and $\mathrm{NaPF}_{6}$-based electrolytes are strongly dependent on the solvents. As shown in Fig. 3(b), only $\mathrm{NaClO}_{4}$ in EC:DMC shows comparable 90 performance with the NaDFOB-based electrolytes, while the others display varying degrees of inferior properties (15-20\%, $48-72 \%$, and $21-85 \%$ capacity loss for cells with NaDFOB-, $\mathrm{NaPF}_{6}-$, and $\mathrm{NaClO}_{4}$-based electrolytes after 20 cycles at 300 
$\mathrm{mA} \mathrm{g}^{-1}$, respectively).

It should be noted that the performance of the same electrolyte can vary when coupled with different electrodes. In previous reports, $\mathrm{NaPF}_{6}$ in EC:PC exhibited comparable performance to 5 that of $\mathrm{NaClO}_{4}$ when coupled with hard carbon. ${ }^{20}$ It showed poor cycling performance and rate capability, however, when used with $\mathrm{Na}_{0.44} \mathrm{MnO}_{2}$ electrode in this study. Therefore, further testing on the compatibility of NaDFOB-based electrolytes with other cathode and anode materials such as $\mathrm{Na}_{3} \mathrm{~V}_{2}\left(\mathrm{PO}_{4}\right)_{2} \mathrm{~F}_{3}$ (NVPF) and 10 hard carbon is necessary.
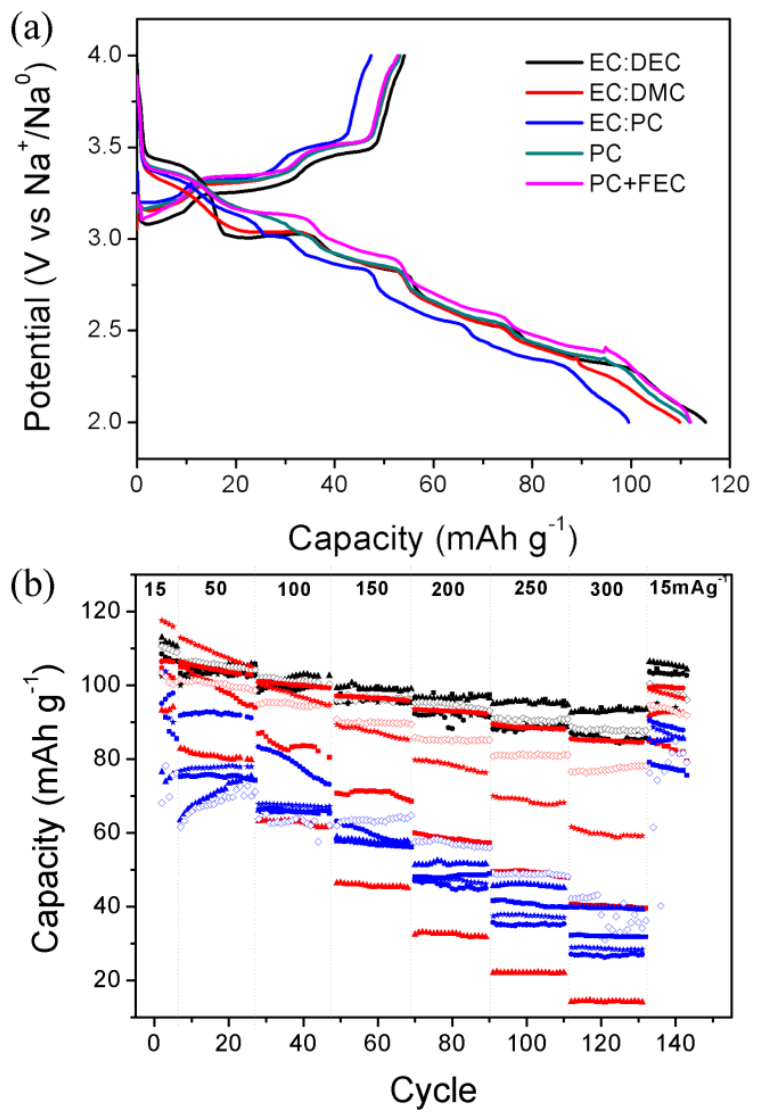

Fig. 3(a) First cycle voltage curves collected at $15 \mathrm{~mA} \mathrm{~g}^{-1}$ of $\mathrm{Na} / \mathrm{Na}_{0.44} \mathrm{MnO}_{2}$ half cells with $1.0 \mathrm{M}$ NaDFOB-based electrolytes. (b) Cycling performances at different rates of $\mathrm{Na} / \mathrm{Na}_{0.44} \mathrm{MnO}_{2}$ half cells using $15 \mathrm{NaX}\left(\mathrm{X}=\mathrm{DFOB}, \mathrm{ClO}_{4}\right.$, and $\left.\mathrm{PF}_{6}\right)$-based electrolytes. $(\boldsymbol{\Delta}=\mathrm{NaDFOB}$ in EC:DEC; = NaDFOB in EC:DMC; $\mathbf{\square}=$ NaDFOB in PC; $\star=$ NaDFOB in EC:PC; $\diamond=\mathrm{NaDFOB}$ in PC $+5 \%$ FEC; $\boldsymbol{\Delta}=\mathrm{NaClO}_{4}$ in EC:DEC; $=\mathrm{NaClO}_{4}$ in EC:DMC; $\mathbf{\square}=\mathrm{NaClO}_{4}$ in PC; $\star=\mathrm{NaClO}_{4}$ in EC:PC; $\diamond=\mathrm{NaClO}_{4}$ in PC+5\%FEC; $\boldsymbol{\Lambda}=\mathrm{NaPF}_{6}$ in EC:DEC; $=\mathrm{NaPF}_{6}$ 20 in EC:DMC; $\mathbf{\square}=\mathrm{NaPF}_{6}$ in PC; $\star=\mathrm{NaPF}_{6}$ in EC:PC; $\diamond=\mathrm{NaPF}_{6}$ in $\mathrm{PC}+5 \% \mathrm{FEC})$

To understand the reasons why NaDFOB-based electrolytes show better performances, we performed ionic conductivity and impedance measurements. Ionic conductivity is one of the key 25 factors affecting cell performance. The conductivity, in turn, depends on several factors, including the degree of dissociation of the salt, the viscosity of the electrolyte, and the transport numbers of the $\mathrm{Na}^{+}$cation and its counter anion. ${ }^{15,} 35$ The viscosity measurement results are displayed in Fig. S9. The solvents 30 largely determine the viscosity, but with NaDFOB-based electrolytes showing lower viscosity than those with the other two salts, with the exception of PC $+5 \%$ FEC-based ones (although still very close). For NaDFOB, the viscosity follows the trend of $\mathrm{PC}+5 \%$ FEC $>$ PC > EC:PC > EC:DEC > ${ }_{35} \mathrm{EC}$ :DMC, which is different from those of $\mathrm{NaClO}_{4}-$ and $\mathrm{NaPF}_{6}$-based electrolytes, indicating that interactions between different anions $\left(\mathrm{X}=\mathrm{DFOB}, \mathrm{ClO}_{4}\right.$, and $\mathrm{PF}_{6}$ ) and the solvents have a marked impact on the viscosity. The conductivity values of $\mathrm{NaDFOB}$ are on the same order of magnitude as those of $40 \mathrm{NaPF}_{6}$ and $\mathrm{NaClO}_{4}$ (although slightly lower), as shown in Fig. S10. A similar trend has been observed for $\mathrm{LiX}(\mathrm{X}=\mathrm{DFOB}$, $\mathrm{ClO}_{4}$, and $\mathrm{PF}_{6}$ ) based electrolytes, where $\mathrm{LiPF}_{6}$ has the highest conductivity due to the low polarizing character of the $\mathrm{PF}_{6}{ }^{-}$ anion, which, in turn, improves salt dissociation and enhances ${ }_{45}$ ionic mobility. ${ }^{36}$ The conductivities of the NaDFOB-based electrolytes follow the trend of EC:DMC > EC:PC > EC:DEC > $\mathrm{PC}>\mathrm{PC}+5 \%$ FEC, which agrees with the observation that solvents with high dielectric constants contribute to the conductivity. ${ }^{20}$

50 The somewhat low ionic conductivities of NaDFOB-based electrolytes are still adequate, as evidenced by the excellent charge/discharge performance (Fig. 3). This high performance is likely to be associated with the good compatibility between the NaDFOB-based electrolyte and the electrode materials. ${ }_{55}$ Electrochemical impedance spectroscopy (EIS) measurements of $\mathrm{Na} / \mathrm{Na}_{0.44} \mathrm{MnO}_{2}$ half cells containing different electrolytes were then carried out (Fig. S11). In all cases, the EIS spectra show either one semicircle or two partially overlapping semicircles, followed by a straight sloping line at the low frequency end. The

60 high frequency semicircle in the EIS is associated with the resistance of the interface between the electrolyte and the electrodes. The medium frequency semicircle is related to the charge-transfer resistance. The following straight sloping line at the low frequency end is mainly related to the diffusion process 65 of Na ions through the electrode-electrolyte. The cells containing NaDFOB-based electrolytes have slightly lower impedances than those with $\mathrm{NaClO}_{4}$ and $\mathrm{NaPF}_{6}$, as shown in Fig. S11.

Safety becomes more critical when large NIB stacks are used for stationary energy storage. The DSC tests (Fig. S6) have 70 shown that NaDFOB-based electrolytes are highly stable up to $80{ }^{\circ} \mathrm{C}$. Since NaDFOB contains F, testing for corrosive HF acid formation upon contact with $\mathrm{H}_{2} \mathrm{O}$ was carried out by the addition of water to the salt. As shown in the ${ }^{11} \mathrm{~B}$ NMR spectra (Fig. S12), hydrolytic products such as $\mathrm{H}_{3} \mathrm{BO}_{3}$ (21-17 ppm), $\left[\mathrm{BF}_{3} \mathrm{OH}\right]^{-}$

75 species $(0.1 \mathrm{ppm})$, and $\mathrm{NaBF}_{4}(-1.5 \mathrm{ppm}$, present in the as-synthesized material) were observed. ${ }^{37}$ In contrast to $\mathrm{NaPF}_{6}$, the ${ }^{19} \mathrm{~F}$ NMR spectra of NaDFOB (Fig. S13) show no sign of dangerous $\mathrm{HF}$ acid, which is a great improvement with respect to safety.

\section{${ }_{80}$ Conclusions}

A new electrolyte salt, $\mathrm{NaDFOB}$, has been synthesized via the reaction between $\mathrm{Na}_{2} \mathrm{C}_{2} \mathrm{O}_{4}$ and $\mathrm{BF}_{3}$.ether. The unique characteristics of $\mathrm{NaDFOB}$-based electrolytes include comparable ionic conductivity with electrolytes containing ${ }_{85} \mathrm{NaClO}_{4}$ and $\mathrm{NaPF}_{6}$, lower viscosity, and a wide electrochemical window. $\mathrm{Na} / \mathrm{Na}_{0.44} \mathrm{MnO}_{2}$ half cells coupled with $\mathrm{NaDFOB}$-based electrolytes exhibit greatly enhanced rate capabilities and cycling performance over those with the commercially available salts, 
and outperform most literature results. In strong contrast to the solvent-dependent performances of $\mathrm{NaClO}_{4}$ and $\mathrm{NaPF}_{6}$ in this study, NaDFOB has high compatibility with various common solvents used for NIBs, meaning that NaDFOB could be highly 5 effective for the exploration of various electrode materials for NIBs. The complex interactions of NaDFOB electrolyte (coupled with different solvents) with various electrode materials such as oxides and alloys certainly necessitate further work to test its full potential as a high performance electrolyte for the emerging NIBs.

\section{${ }_{10}$ Notes and references}

${ }^{a}$ Institute for Superconducting and Electronic Materials, Innovation Campus, University of Wollongong, Squires Way, North Wollongong, NSW 2522, Australia. Fax: +61 024221 5731; Tel: +61 024221 3220; E-mail: zhenguo@uow.edu.au

$15^{b}$ Intelligent Polymer Research Institute, ARC Centre of Excellence for Electromaterials Science, Innovation Campus, University of Wollongong, Squires Way, North Wollongong, NSW 2522, Australia.

c College of Environmental and Chemical Engineering, Shanghai University of Electric Power, Shanghai 200090, China

$20{ }^{d}$ School of Chemistry, University of Wollongong, Wollongong, New South Wales, 2522, Australia

† Electronic Supplementary Information (ESI) available: FTIR spectra,

XRD patterns, crystal structure of NaDFOB, DSC curves, CV curves,

Coulombic efficiencies, viscosity values, conductivity values, EIS, ${ }^{11} \mathrm{~B}$ 25 NMR, and ${ }^{19}$ F NMR spectra. See DOI: 10.1039/b000000x/

1. N. Yabuuchi, K. Kubota, M. Dahbi and S. Komaba, Chem. Rev., 2014, 114, 11636-11682.

2. D. Kundu, E. Talaie, V. Duffort and L. F. Nazar, Angew. Chem. Int.

$30 \quad$ Ed., 2015, 54, 3431-3448.

3. M. D. Slater, D. Kim, E. Lee and C. S. Johnson, Adv. Funct. Mater., 2013, 23, 947-958.

4. H. Pan, Y.-S. Hu and L. Chen, Energy Environ. Sci., 2013, 6, 23382360.

35 5. S.-W. Kim, D.-H. Seo, X. Ma, G. Ceder and K. Kang, Adv. Energy Mater., 2012, 2, 710-721.

6. B. L. Ellis and L. F. Nazar, Curr. Opin. Solid State Mater. Sci., 2012, 16, 168-177.

7. V. Palomares, P. Serras, I. Villaluenga, K. B. Hueso, J. Carretero-

$40 \quad$ Gonzalez and T. Rojo, Energy Environ. Sci., 2012, 5, 5884-5901.

8. M. S. Islam and C. A. J. Fisher, Chem. Soc. Rev., 2014, 43, 185-204.

9. M. H. Han, E. Gonzalo, G. Singh and T. Rojo, Energy Environ. Sci., 2015, 8, 81-102.

10. N. Yabuuchi and S. Komaba, Sci. Technol. Adv. Mater., 2014, 15, $45 \quad 043501$

11. Y. Kim, K. H. Ha, S. M. Oh and K. T. Lee, Chem. Eur. J., 2014, 20, 11980-11992.

12. V. Palomares, M. Casas-Cabanas, E. Castillo-Martinez, M. H. Han and T. Rojo, Energy Environ. Sci., 2013, 6, 2312-2337.

50 13. L. P. Wang, L. Yu, X. Wang, M. Srinivasan and Z. J. Xu, J. Mater. Chem. A, 2015.

14. Z. Zhu, H. Li, J. Liang, Z. Tao and J. Chen, Chem. Commun., 2015, 51, 1446-1448.

15. K. Xu, Chem. Rev., 2004, 104, 4303-4418.

55 16. K. Xu, Chem. Rev., 2014, 114, 11503-11618.

17. A. Ponrouch, D. Monti, A. Boschin, B. Steen, P. Johansson and M. Palacín, J. Mater. Chem. A, 2015, 3, 22-42.
18. X. Xia, W. M. Lamanna and J. R. Dahn, J. Electrochem. Soc., 2013, 160, A607-A609.

60 19. C. Ge, L. Wang, L. Xue, Z.-S. Wu, H. Li, Z. Gong and X.-D. Zhang, J. Power Sources, 2014, 248, 77-82.

20. A. Ponrouch, E. Marchante, M. Courty, J.-M. Tarascon and M. R. Palacin, Energy Environ. Sci., 2012, 5, 8572-8583.

21. A. Bhide, J. Hofmann, A. K. Dürr, J. Janek and P. Adelhelm, Phys. 65 Chem. Chem. Phys., 2014, 16, 1987-1998.

22. A. Ponrouch, R. Dedryvere, D. Monti, A. E. Demet, J. M. Ateba Mba, L. Croguennec, C. Masquelier, P. Johansson and M. R. Palacin, Energy Environ. Sci., 2013, 6, 2361-2369.

23. K. Xu, S. S. Zhang, U. Lee, J. L. Allen and T. R. Jow, J. Power 70 Sources, 2005, 146, 79-85.

24. P. Y. Zavalij, S. Yang and M. S. Whittingham, Acta Crystallogr., Sect. B: Struct. Sci., 2003, 59, 753-759.

25. S. Shui Zhang, Electrochem. Commun., 2006, 8, 1423-1428.

26. V. Aravindan, P. Vickraman and K. Krishnaraj, Polym. Int., 2008, $75 \quad$ 57, 932-938.

27. H. Zhou, F. Liu and J. Li, J. Mater. Sci. Technol., 2012, 28, 723-727.

28. J. L. Allen, S.-D. Han, P. D. Boyle and W. A. Henderson, J. Power Sources, 2011, 196, 9737-9742.

29. F. Sauvage, L. Laffont, J. M. Tarascon and E. Baudrin, Inorg. $80 \quad$ Chem., 2007, 46, 3289-3294.

30. Y. Cao, L. Xiao, W. Wang, D. Choi, Z. Nie, J. Yu, L. V. Saraf, Z. Yang and J. Liu, Adv. Mater., 2011, 23, 3155-3160.

31. P. Zhan, S. Wang, Y. Yuan, K. Jiao and S. Jiao, J. Electrochem. Soc., 2015, 162, A1028-A1032.

85 32. E. Hosono, T. Saito, J. Hoshino, M. Okubo, Y. Saito, D. NishioHamane, T. Kudo and H. S. Zhou, J. Power Sources, 2012, 217, 4346.

33. L. Zhao, J. Ni, H. Wang and L. Gao, RSC Adv., 2013, 3, 6650-6655.

34. R. Berthelot, D. Carlier and C. Delmas, Nat. Mater., 2011, 10, 7480.

35. M. S. Ding and T. Richard Jow, J. Electrochem. Soc., 2004, 151, A2007-A2015.

36. S.-D. Han, O. Borodin, J. L. Allen, D. M. Seo, D. W. McOwen, S.H. Yun and W. A. Henderson, J. Electrochem. Soc., 2013, 160,

$95 \quad$ A2100-A2110.

37. S. Zugmann, D. Moosbauer, M. Amereller, C. Schreiner, F. Wudy, R. Schmitz, R. Schmitz, P. Isken, C. Dippel, R. Müller, M. Kunze, A. Lex-Balducci, M. Winter and H. J. Gores, J. Power Sources, 2011, 196, 1417-1424. 